\title{
Response Surface Methodology for 30 kW PEMFC stack characterization
}

\author{
Eleonora Gadducci , Stefano Saccaro, Massimo Rivarolo, Loredana Magistri \\ DIME, University of Genoa, Via Montallegro 1, 16145 Genoa, Italy
}

\begin{abstract}
Hydrogen is a promising energy carrier to allow the reach of the zero-emission targets established for the next years. Polymeric Electrolyte Membrane FC are studied inside the HI-SEA laboratory of the University of Genoa, to assess the opportunities of this technology on marine applications. Here, 8 PEMFC stacks, sized $30 \mathrm{~kW}$ each for a total power installation of $240 \mathrm{~kW}$, have been tested to draw guidelines for the best system design onboard ships and to deepen the know-how on the experimental management of the technology. During the tests, it was possible to observe the reciprocal influence of some parameters, which may influence the system efficiency. In this work, a statistical investigation is developed to quantify the cell voltage variation correlated to the values of temperature and current. This has been possible thanks to Design Expert (DE), a software developed by Stat-EASE, Inc. Through the Design of Experiment approach, it is possible to evaluate the significance of variables in the FC system, called factors. The experiment under consideration is also characterized by non-controllable factors, cause of disturbances that induce further variability in the response. Eventually, it was possible to analyse the significance of the parameters involved, to build a regression model by performing the analysis of variance with which the significant values are identified, and to assess the presence of outliers.
\end{abstract}

\section{Introduction}

The impact of the shipping sector on global Green House Gases (GHG) emissions is not negligible, and actions must be taken in order to reach the ambitious targets on emissions set at $2050[1,2]$. Indeed, under a business-asusual scenario, emissions could increase between 50 and $250 \%$ by 2050 , [3,4], mining the Paris Agreement objectives [5].

Under these new constraints, innovative technologies are studied that employ alternative and low-carbon fuels. Among others, hydrogen is a very promising energy carrier; it can be employed as a reactant in Fuel Cell (FC) technology, where it undergoes an electrochemical reaction producing an outlet flow and electrical energy. Polymeric Electrolyte Membrane FCs (PEMFC) are in particular interesting for transport applications, where they can be employed to power low and heavy-duty vehicles, trains as well as shipping vessels of different sizes [6-8]. For this reason, different studies have been focusing on assessing the use of this technology on real scale applications even in hybrid configurations coupled with batteries [9-16], also detailing the different opportunities and limitations of producing [17] and storing the hydrogen gas safely onboard [18].

However, the lack of international legislations regarding the installation of Fuel Cell Systems (FCS) on ships, together with a poor experience on real-size systems, are delaying the spread of the technology and the optimization of dedicated control systems. In this context, the HI-SEA (Hydrogen Initiative for Sustainable Energy Applications) Laboratory of the University of Genoa [19] offers an interesting opportunity to deepen the research on a $240 \mathrm{~kW} \mathrm{FCS}$, complete with auxiliary components. This infrastructure has seen different experimental campaigns developing the assessment of the Balance of Plant (BoP) components adequacy to withstand naval environmental and operative conditions [20,21]. The results obtained also gave some hints to identify the most influent operative parameters that determine the global efficiency of the system, which are taken as the starting point for the present study.

\subsection{Design of Experiments and Response Surface Methodology}

In stochastic systems, such as the one under consideration, specific statistical techniques are used to determine the effect that input parameters have on the output variable (objective function). The aim of the Design of Experiments (DoE) techniques, is to determine the influence on a selected objective function for one or more independent variables (named factors), varying among different levels or treatments. The significance of such factors is determined through a statistical comparison of the average of the observations under each treatment $[22,23]$. This process is carried out in order to establish which factors determine a significant variation of the objective function. The experiment is also characterized by uncontrollable factors, which are the

\footnotetext{
* Corresponding author: eleonora.gadducci@edu.unige.it
} 
cause of disturbances or background "noises", which induce further variability of the response.

An important evolution of DoE is the so-called Response Surface Methodology (RSM) that aims to define the optimal design (the grid of candidate points in the experimental region) in order to build regression models for the objective function.

To fit a first-order regression model, the RSM identifies as best experimental design the Two-Level Factorial Design. To fit second order regression models, the Central Composite Design (CCD) or the FaceCentered Central Composite (FCC) design are adopted.

The statistical analysis and graphical analysis of the data were performed by using Design Expert software (Version 12.0, Stat-Ease, USA).

Thanks to the development of experimental tests on the HI-SEA system, a number of different parameters can be collected. The postprocessing of these data can be employed to create a regression model of the system, as the ones developed in previous studies such as [24-33]. In this work, the effect of cooling temperature on cell voltage has been deepened.

\section{The HI-SEA system}

The HI-SEA system is made up by 8 PEMFC stacks supplied by Nuvera Fuel Cells, model Orion ${ }^{\circledR}$. All auxiliaries and fuel cells that make up a single entity capable of delivering power are identified with the name of FC "stack". The latter operate with pure hydrogen and air as reactants, producing water as the only exhaust. These stacks, born for automotive applications, have been described in detail in a previous work by the authors [21]; each of them is sized $30 \mathrm{~kW}$ and has around 200 cells. The cells work with a slight excess of hydrogen and with a more significant excess of air with respect to stoichiometric requirements. The unreacted hydrogen is recirculated, while unreacted air is eliminated through the same line designated for the exhaust reaction water produced by the electrochemical reactions. The whole system has been designed to simulate the installation on a real vessel, and therefore it is assembled inside a $30 \mathrm{ft}$ container. The cathodic delivery line is supplied by an industrial compressor to simulate the connection to the compressed air line present onboard, the cooling temperature is regulated by a two-stage cooling circuit that simulates the heat exchange with sea water, and finally the load profiles can be tested through a resistive electric load to prove the ability of the installation to follow different power requests. The previous experimental campaigns have confirmed that the system is compliant with shipping operation requirements $[21,35]$, however some general instabilities emerged. The latter were mainly due to the intrinsic behaviour of the air delivery circuit, where the industrial compressor follows a start and stop dynamic, and to the cooling temperature control. The effect was especially visible on the value of cell voltage, which during the tests is taken as the reference to evaluate the general performance of the $\mathrm{FC}$, and it was amplified by the natural aging of the cells themselves. In fact, the cells were assembled first in
2014, then they underwent harsh test conditions and eventually were left unemployed during three years before their rearrangement inside the HI-SEA Lab. Although a dedicated test campaign managed to reestablish a good system performance through a recovery procedure [34], the cells weakness remains visible and is influenced by other components of the system.

\subsection{System layout and control}

The FCS is made up of 8 stacks, divided into 2 parallel branches. Inside a branch they are connected in electrical series, and the parallel operation is possible thanks to the presence of $2 \mathrm{DC} / \mathrm{DC}$ converters, that set the voltage output on the same value so that the load is equally shared. In this way, voltage differences between the stacks - that may arise from different aging of the cells or from temporary unfavourable operating conditions - are not an issue to load repartition.

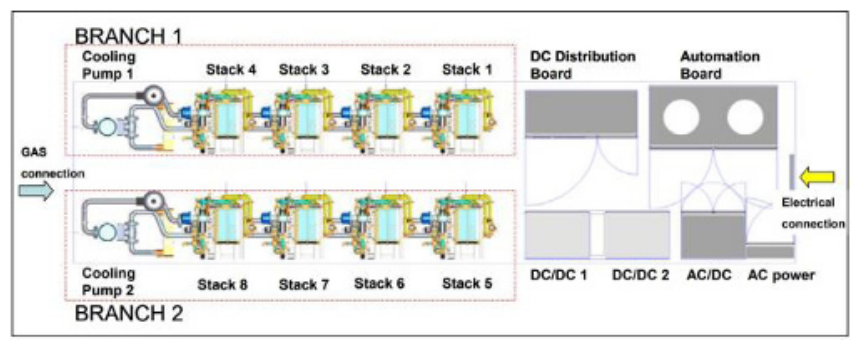

Fig. 1. Layout of the HI-SEA system.

The control of the HI-SEA system consists of a supervision system and a local panel that contains the Programmable Logic Controller (PLC) type GE IP Rx3i, an I/O field, power supplies and all auxiliary accessories for the management of communication lines; the supervisory computer interfaces to the PLC and performs the monitoring and historicization of all process variables, as well as manages the Human-Machine Interface (HMI) also implementing all the procedures to provide standard security levels for the access to the information. The control PLC performs the interfacing, management, and coordination of field devices, using when necessary different communication standards.

One of the tasks assigned to the system is to control and regulate the control circuits of fuel cells; the software is designed to control up to 8 stacks, however the operating logic of all stacks is perfectly identical to each other. One of the most important parts of the control system is the Cell Voltage Monitoring (CVM). As cell voltage is a very important indicator of the performance as well as of the state of health of cells [36,37], this value must be carefully handled and considered. The CVM chosen by Nuvera Fuel Cells acquires every second the voltage value of each cell in the stacks; therefore, it saves and communicates to the control system - for each FC stack - the following data:

- Minimum cell voltage: the lowest voltage value measured in a stack, and the ID of the cell where it is measured 
- Maximum cell voltage: the highest voltage value measured in a stack, and the ID of the cell where it is measured

- Average cell voltage: obtained dividing the total stack voltage by the number of cells.

The cell voltage values are therefore employed in the analysis described in this work, to evaluate the influence of other parameters on the global FC performance. Minimum cell voltage is particularly interesting for the study, as it is usually linked to the weakest cell in a stack. In this case, it will immediately hint the presence of a non-optimized operating condition.

Another crucial aspect of the control system is the cooling circuit. The most suitable operating temperature has been set by the FC supplier to keep the ideal relative humidity on the membranes. The maintenance of the correct cell temperature is ensured by the cooling circuit, which regulates the temperature and mass flow rate of the cooling flow that removes the excess heat from the cells by means of a heat exchanger. The regulation is led by the measured current.

\subsection{Tests description}

To evaluate the influence of the operative conditions on cell voltage, a dedicated test campaign has been defined. In normal operation, the cell's potential follows a wellknown trend that depends on the current density. The generic polarization curve represented in Figure 2 describes the typical correlation between current and voltage in a PEMFC.

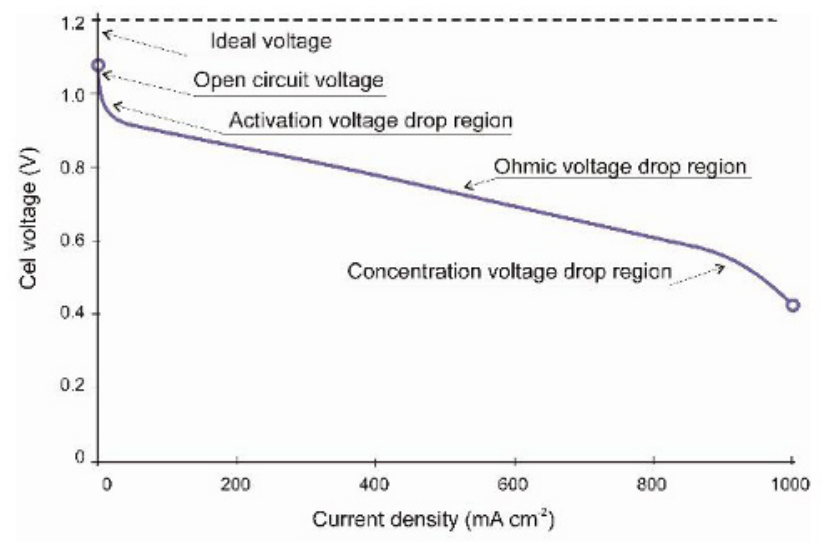

Fig. 2. Typical polarization curve of a PEMFC [38].

Due to the different losses - namely activation, ohmic and concentration losses [38] - the voltage tends to decrease with the increasing current, but with a different slope depending on the value of the latter. For this reason, in order to start the RSM analysis on the HI-SEA system, it was chosen to initially develop constant load tests, to avoid incurring in misleading cell voltage variations due to different load request and not to the system's instabilities under investigation. The constant load tests have the objective of verifying if the system is adequate for the operation. The tests have been implemented at different loads: 10, 20, and $30 \mathrm{~kW}$ per stack. This choice was made to ensure that the whole operative range indicated by the FC supplier was actually exploitable, kept a good performance and would not cause excessive stress to the cells. After the development of the tests, the acquired data has been postprocessed and inserted in DE software. To analyse the total stack voltage as a function of temperature and current, the following steps are taken:

- Current and cooling temperature are considered as the quantitative independent variables to be analysed.

- Maximum and minimum values of the independent variables are identified.

- Total stack voltage is considered as the objective function.

- The presence of outliers is issued, as they can distort the results of the analyses.

- The software DE evaluates the significance of the analysed variables and builds a representative regression model.

- The ANOVA allows the evaluation of significative and non-significative terms ( $p$-value $>0,05$ ).

This process has been applied to all the stacks, whereas only the results related to one stack of the system (number 7) for an output power of $20 \mathrm{~kW}$ are reported in the results, as this FC stack is the most stable during operation, considering the average quadratic deviation relative to the stack voltage.

\section{Results}

After analyzing the influence of the cooling temperature, a regression model is built. The V-I correlation is carried out using the temperature as a parameter, with the aim of building a map through the characteristic curves drawn at different power setpoints; through this map, it will be possible to act on the control system to implement a more precise performance monitoring.

The three main outputs of the study are:

- The survey domain, represented in Figure 3: relative to the total cell voltage, it shows the contour lines and, depending on the red or blue colour, it gives an indication of the increase or decrease of the objective function (voltage) linked to the parameters change (current and temperature).

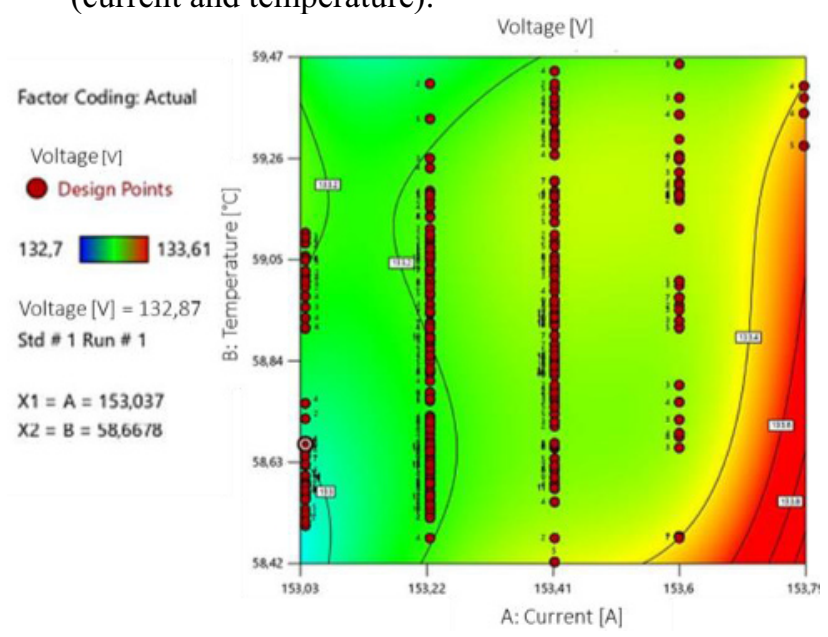

Fig. 3. Survey domain of total stack voltage, stack n.7, $20 \mathrm{~kW}$. 
- Response surface, represented in Figure 4: for each investigation domain, Design Expert builds a response surface that represents the behaviour of the output variable as a function of the input factors in the investigated ranges. The surface is represented through a $3 \mathrm{D}$ graph. For this analysis, it must be considered that the sampled data, being collected during the tests on the HI-SEA system, can make the experiment result unbalanced. This means that in the domain there are some areas where no experimental answers are available, and where an incorrect approximation of the response is verified leading to an unreliable response surface at those points. To delimit the problem, an appropriate domain cut can be made in order to analyse only the area where the experimental data are located, in order to make the statistical analysis more reliable.

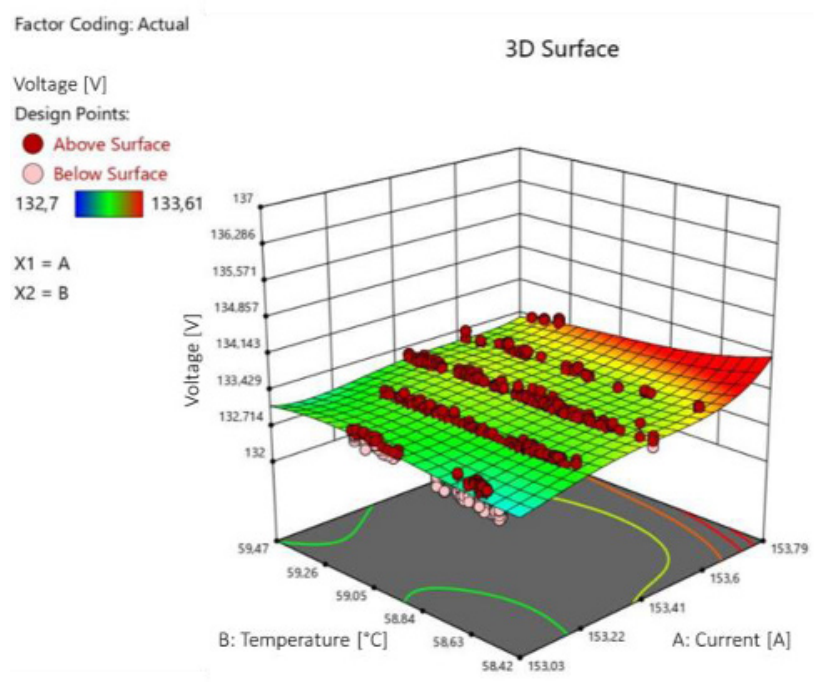

Fig. 4. Response surface, stack n.7, $20 \mathrm{~kW}$.

Since no imbalance areas to be cut have been identified, the analysis is carried out of the confidence interval.

- Confidence interval, represented in Figures 5 and 6: once the most suitable response surface has been identified, the confidence intervals are analyzed, which represent the fields of variation where one expects to find the answers of the system. Each interval has a confidence level associated with it that represents the statistical probability that that range contains the true value of the answer; specifically, the level used is equal to $95 \%$.

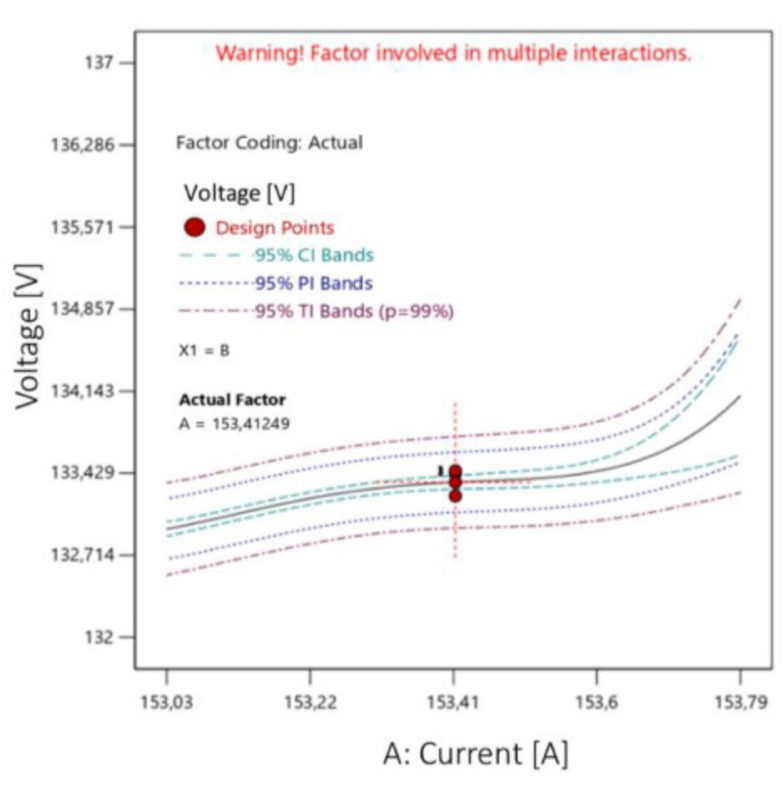

Fig. 5. Confidence interval for total stack voltage, stack n.7, 20 $\mathrm{kW}$; current is set at $153,41 \mathrm{~A}$.

For each domain, one single current value is set, as the variations for this parameter are small and mainly due to the control of the resistive load. The current value for the confidence interval is set at $153.41 \mathrm{~A}$, as this value was the most measured during the tests at $20 \mathrm{~kW}$. As regards the cooling temperature, it is set at $58,42{ }^{\circ} \mathrm{C}$, corresponding to the most measured value assumed during the tests at $20 \mathrm{~kW}$. The lines in figures 4 and 5 represent the trend of total voltage of stack n.7 and its confidence intervals for a $20 \mathrm{~kW}$ power output. These maps can be the starting point to develop a precise monitoring system: when voltage is measured, if it lays within the confidence interval thus the system is operating correctly. Otherwise, a warning is reported as some anomalies may be ongoing.

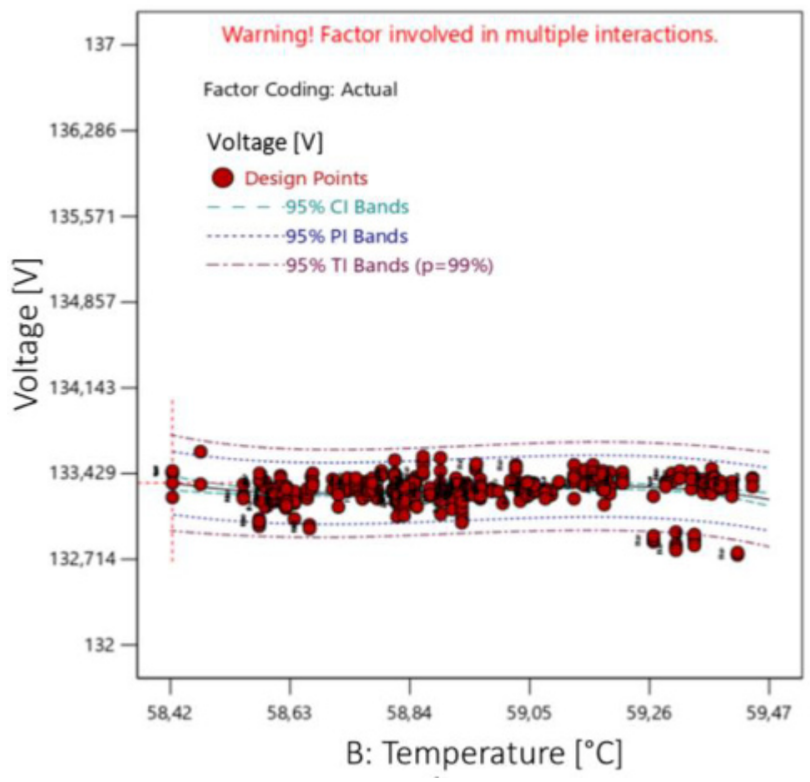

Fig. 6. Confidence interval for total stack voltage, stack n.7, 20 $\mathrm{kW}$; cooling temperature is set at $58,42{ }^{\circ} \mathrm{C}$. 


\section{Conclusions}

The HI-SEA system is a real scale laboratory sized $240 \mathrm{~kW}$ of a PEMFC installation for shipping applications. The size of the FC system is compliant with the adopted ones in real world applications: PEMFC systems of similar size are already installed or are planned for future hydrogen-based vessels, such as the Italian ZEUS vessel by Fincantieri (tests in open sea are foreseen in 2022) [18]. For this reason, the HI-SEA system acquires relevance as a baseline study for the future of PEMFC applications in the maritime field, considering the lack of experimental results on real-scale systems in literature. Its BoP is made up of components that represent the naval environment; however, such components can create instabilities on the system which have an effect on the FC performance and in particular on the voltage. A Design of Experiment approach has been applied to the experimental data acquired during constant load tests, to verify the influence of current and cooling temperature oscillations, classified as the independent variables, on the objective function - the total stack voltage. The results, reported for the representative case study of stack n.7 for a power output of $20 \mathrm{~kW}$, are obtained through the software Design Expert. The latter allowed to draw the survey domain, the Response Surface and the confidence intervals of the stack voltage for the case study and can become the reference for the creation of a precise performance monitoring system for the PEMFC installation: if the stack voltage lays out of the confidence intervals, anomalies can be rapidly detected, reducing significantly the operation in stressing conditions that can affect the state of health of the PEMFCs.

\section{References}

1. International Maritime Organization (IMO). Third greenhouse gas study. 2015.

2. https://www.imo.org/en/MediaCentre/HotTopics/Pag es/Reducing-greenhouse-gas-emissions-fromships.aspx, International Maritime Organization (IMO) official website, last access 22/01/2021

3. Maritime forecast to 2050-Energy transition outlook. DNV-GL Maritime (2019)

4. Setting the course to low carbon shipping. American Bureau of Shipping (ABS); (2019)

5. United Nations. Framework convention on climate change (UNFCCC). Paris Agreement; (2015)

6. M. Rivarolo, D. Rattazzi, T. Lamberti, L. Magistri. Int J Hydrogen Energy;45 ;25747-57 (2020)

7. H. Sapra, J. Stam, J. Reurings, L. van Biert, W. van Sluijs, P. de Vos, et al. Appl Energy;281:115854 (2021)

8. M. Rivarolo, D. Rattazzi, L. Magistri, A.F. Massardo, En. Conv. And Management, 244, 114506 (2021)

9. O.B. Inal, C. Deniz, J Clean Prod; 265; 121734 (2020)
10. P. Wu, R. Bucknall, Int J Hydrogen Energy;45:3193208 (2020)

11. H. Nazir, N. Muthuswamy, C. Louis, S. Jose, J. Prakash, M. Buan, et al. Int J Hydrogen Energy; 45 ; 28217-39 (2020)

12. A. Pfeifer, P. Prebeg, N. Duic, E Transportation;3:100048 (2020)

13. C. Nuchturee, T. Li, H. Xia, Renew Sustain Energy Rev;134:110145 (2020)

14. S.E : Hosseini, Modul. Earth syst. Environ. Sci.. Elsevier; (2020)

15. A.L. Dicks, Modul. Earth syst. Environ. Sci.. Elsevier; (2020)

16. A. Bouakkaz, A.J.G. Mena, S. Haddad, M.L. Ferrari, Journal of Energy Storage, 33, pp.101887_1-13 (2021)

17. D. Bellotti, M. Rivarolo, L. Magistri, A.F. Massardo, International Journal of Hydrogen Energy, 40, pp.2433-2444 (2015)

18. M. Cavo, E. Gadducci, D. Rattazzi, M. Rivarolo, L. Magistri, Int H Hydrogen Energy, 46, 32630-32644 (2021)

19. http://www.tpg.unige.it/TPG/

20. G. Borgogna, E. Speranza, T. Lamberti, A.N. Traverso, L. Magistri, E. Gadducci, et al. E3S Web Conf.;113:1-8 (2019)

21. E. Gadducci, T.Lamberti, D. Bellotti, L. Magistri, A.F : Massardo, Int J Hydrogen Energy ;46(47):24305-17 (2021)

22. D.C. Montgomery, John Wiley \& Sonc, Inc. (1997/2005)

23. R.H. Meyers, D.C. Montgomery, John Wiley \& Sons, Inc. (1995)

24. S.J. Cheng, J.M. Miao, S.J. Wu, Applied Energy, 105, 161-169 (2013)

25. M. Ghasabehi, M. Shams, H. Kanani. Energy Conversion and Management, 230, 113798 (2021)B. Wahdame, D. Candusso, F. Harel, X. François, M.C. Péra, D. Hissel, J.M. Kauffmann, Journal of Power Sources, 182, 429-440 (2008)

26. H. Kanani, M. Shams, M. Hasheminasab, A. Bozorgnezhad, Energy Conversion and Management, 93, 9-22 (2015)

27. G. Correa, F. Borello, M. Santarelli, International Journal of Hydrogen Energy, 40, 10354-10365 (2015)

28. L. Jin, X.J. Wang, J.W. Zhu, et al. Energy Conversion and Management, 228, 113727 (2021)

29. K. Charoen, C. Prapainainar, P. Sureeyatanapas, et al. Journal of Cleaner Production, 142, 1309-1320 (2017)

30. T. Jahnke, G. Futter, A. Latz, et al. Journal of Power Sources, 304, 207-233 (2016)

31. F. Mahmoodi, R. Rahimi, Applied Thermal Engineering, 178, 115490 (2020)

32. S. Jeon, D. Cha, H. Kim, Y. Kim, Applied Energy, 166, 165-173 (2016) 
33. M. Moein-Jahromi, M.J. Kermani, Energy Conversion and Management, 231, 113837 (2021)

34. E. Gadducci, T. Lamberti, L. Magistri, Proceedings of EFC2019, 231-232 (2020)

35. Gadducci, T. Lamberti, L. Magistri, Proceedings of EFC2019, 235-236 (2020)
36. P. Pei, Y. Li, H. Xu, Z. Wu, Appl Energy, 173, 366385 (2016)

37. E. Ramschak, V. Peinecke, P. Prenninger, T. Schaffer, W. Baumgartner, V. Hacker, Fuel Cell Bull, 12-15 (2006)

38. J.C. Amphlett, J Electrochem Soc, 142, 9 (1995) 